\title{
RPG4Sorting - Um Jogo Educacional para Auxílio ao Ensino de Métodos de Ordenação
}

\author{
Isabella de Freitas Nunes', Paulo Afonso Parreira Júnior¹ \\ ${ }^{1}$ Universidade Federal de Goiás (UFG) \\ Jataí - GO - Brasil \\ isabelladefreitasnunes@gmail.com,paulojunior@jatai.ufg.br
}

\begin{abstract}
This article shows an educational game, named RPG4Sorting, which has the objective of improving the interaction among students and teachers during the teaching / learning process of sorting methods. The major difference of this game to others that exists in literature is that this is a board game with RPG elements (Role-Playing Game). The main advantage of a board game with RPG elements is the real time interaction provided to the players, which is an important attribute in educational games. In an evaluation performed with undergraduate students in Computer Science, the RPG4Sorting was highly rated on attributes related to social interaction and user experience. The game, however, shows weaknesses in terms of fun and user satisfaction.
\end{abstract}

Resumo. Este artigo apresenta um jogo educacional, denominado RPG4Sorting, cujo intuito é aprimorar a interação entre alunos e professores durante o processo de ensinoaprendizagem de métodos de ordenação. O grande diferencial deste jogo em relação aos demais existentes na literatura é o fato de ele ser um jogo de tabuleiro no estilo RPG (RolePlaying Game). A principal vantagem de um jogo de tabuleiro neste estilo é que ele permite a interação em tempo real entre os seus jogadores, o que consiste em um elemento importante para um jogo educacional. Em uma avaliação realizada com alunos de graduação em Ciência da Computação, o RPG4Sorting foi bem avaliado em atributos relacionados à interação social e experiência do usuário, porém, apresentou fragilidades em termos de divertimento e satisfação dos usuários.

\section{Introdução}

Presente em uma ou mais disciplinas da maioria dos cursos de graduação das áreas de Tecnologia da Informação, as Estruturas de Dados (EDs) compreendem componentes curriculares de suma importância para a compreensão de problemas clássicos da Ciência da Computação. É sabido que alunos de graduação tem apresentado dificuldades no entendimento dos tópicos relacionados às EDs, o que têm gerado um alto nível de evasão e de reprovação nas disciplinas em que esses tópicos são apresentados [Wiedenbeck et al., 2014; Colaso et al., 2002; Júnior et al., 2005].

Segundo Boticki et al. (2012), em geral, os alunos estudam e aprendem EDs utilizando o papel e a caneta, realizando testes de mesa e replicando os passos descritos pelo código fonte de um determinado algoritmo. Este método é considerado cansativo e ineficiente, muitas vezes resultando em erros, ora na sequência de passos do algoritmo, ora na simulação de uma sequência de passos incorretos. Essas situações podem fazer com que o aluno se distraia e, no pior caso, que seja induzido ao erro. Um conteúdo relacionado às EDs que geralmente "sofre" com tal estratégia é aquele relacionado aos métodos de ordenação. Isso porque esses métodos envolvem longas sequências de passos algorítmicos para que o conjunto seja ordenado.

A fim de melhorar a experiência dos alunos com as disciplinas que envolvem programação e estruturas de dados, diversos pesquisadores têm buscado alternativas a serem aplicadas no âmbito da sala de aula, cujo objetivo é melhorar a visualização dos algoritmos e resgatar o interesse dos alunos para esses conteúdos [Baker et al., 1999; Barbosa e Parreira Júnior, 2013]. Entre elas estão a proposta de utilizar atividades 
lúdicas, tais como jogos e ferramentas educacionais e softwares de simulação, entre outros [Colaso et al., 2002].

A vantagem dos jogos educacionais perante as demais ferramentas educacionais, tais como filmes, slides e ferramentas educacionais digitais, é que nestas últimas, apesar de apresentarem representações gráficas, há pouca ou nenhuma interação entre os alunos e os conceitos estudados na disciplina. Segundo Battistella et al. (2012), essa falta de interação pode: (i) levar o aluno a se distrair durante a execução de algum passo importante de um algoritmo, o que poderia levá-lo a não compreensão total do conceito abordado; e (ii) fazer com que o aluno se entedie e não volte a utilizar o recurso de aprendizagem.

Há algumas propostas de jogos educacionais para ensino de EDs, em particular, de métodos de ordenação [Boticki, I. et al., 2012; Battistella et al., 2012; Hakulinen, 2011], contudo, a maioria dessas propostas se baseia em jogos single-player, nos quais não há interação social em tempo real entre os jogadores. Além disso, a maioria dos jogos propostos é digital, o que exige que os alunos estejam em ambientes com dispositivos computacionais para poder jogá-los.

Este trabalho apresenta um jogo educacional de apoio ao ensino de métodos de ordenação, denominado RPG4Sorting. O grande diferencial deste jogo em relação aos demais existentes na literatura é o fato de ele ser um jogo de tabuleiro no estilo RPG (Role-Playing Game). Segundo Hitchens e Drachen (2009), a principal vantagem de um jogo de tabuleiro neste estilo é que ele permite a interação em tempo real entre os jogadores, se aproveitando da imaginação e dos objetivos propostos para motivar os jogadores a continuarem jogando até o fim, a fim de conhecer os rumos que o roteiro tomará. Outra vantagem do RPG4Sorting é que ele pode ser aplicado em salas de aula convencionais, que não possuam recursos computacionais (Benitti e Molléri, 2008).

O restante deste trabalho está organizado da seguinte forma: (i) a Seção 2 apresenta uma breve descrição de alguns trabalhos relacionados a este; (ii) a Seção 3 apresenta o jogo RPG4Sorting, destacando seus elementos, bem como sua contribuição para o contexto do processo de ensino-aprendizagem; (iii) a Seção 4 destaca os resultados da avaliação realizada com alunos de graduação em computação, a respeito do RPG4Sorting; e (iv) por fim, na Seção 5 estão as considerações finais e propostas de trabalhos futuros.

\section{Trabalhos Relacionados}

Jogos são ferramentas que têm sido intensivamente utilizadas pelos profissionais da área de educação como auxílio para a construção do conhecimento. Segundo Gibson et al. (2006), um jogo educacional caracteriza-se como qualquer atividade com caráter instrucional que envolve competição e regras. Jogos possuem um valor educacional intrínseco, pois agem como elementos motivadores, unindo a vontade e o prazer durante o desenvolvimento de uma atividade, o que pode tornar as aulas mais agradáveis (Silva e Morais, 2011).

Por conta das propriedades encontradas nos jogos, há várias propostas de utilizálos como apoio ao ensino de Estruturas de Dados. Barbosa e Parreira Júnior (2013) conduziram um Mapeamento Sistemático ${ }^{1}$ que teve como objetivo buscar e catalogar ferramentas educacionais de apoio ao ensino de Estruturas de Dados. Neste levantamento, foram encontrados dois estudos propondo jogos educacionais digitais [Boticki, et al., 2012; Battistella et al., 2012] para auxílio ao ensino de métodos de

1 Um Mapeamento Sistemático pode ser visto como uma revisão mais ampla dos estudos primários disponíveis na literatura, com objetivo de identificar a quantidade, os tipos de pesquisas e resultados disponíveis acerca de um determinado assunto que se deseja. Além disso, ele pode indicar a evolução dos estudos na área de pesquisa escolhida ao longo dos anos. 
ordenação e apenas um jogo não digital [Hakulinen, 2011] com a mesma finalidade.

Boticki et al. (2012) apresentaram um jogo educacional para dispositivos móveis, denominado Sortko ${ }^{2}$. Ele apresenta um vetor formado por um conjunto de números inteiros desordenados que o usuário deverá ordenar utilizando algum método de ordenação escolhido por ele. Para ordenar o vetor, o aluno deve seguir as instruções que a cada execução são exibidas no topo do aplicativo e realizar uma ação correspondente. Por exemplo, uma das instruções do jogo é: "compare o segundo elemento com o terceiro elemento da esquerda para a direita, se for maior troque suas posições".

Battistella et al. (2012), desenvolveram um jogo denominado SORTIA ${ }^{3}$, por meio do qual o aluno deve simular manualmente o processo de ordenação de um conjunto de números inteiros, movendo com o mouse cada item que necessita ser alterado de acordo com a iteração do método HeapSort. O jogo foi desenvolvido para ser utilizado de forma individual e em um navegador com suporte a JavaScript e HTML.

Por fim, Hakulinen (2011) apresenta dois jogos de cartas, também utilizados no contexto do ensino de método de ordenação: o SortingGame e o SortingCasino. O SortingGame pode ser jogado por 2 a 6 jogadores. Ele inclui dois baralhos de cartas: as cartas de algoritmos e as cartas especiais. Cada carta de algoritmo possui o nome de um método de ordenação e cada carta especial contém um critério que o jogador pode aplicar ou não para um determinado algoritmo. São exemplos de cartas especiais: algoritmo estável, recursivo, $\mathrm{O}\left(\mathrm{n}^{2}\right)$, entre outros. O objetivo dos jogadores é combinar as cartas dos algoritmos com as cartas especiais de forma correta. Por exemplo, SelectionSort é um método não estável, portanto, não poderia ser combinado com a carta "algoritmo estável". O SortingCasino é semelhante ao jogo anterior, porém todos os jogadores devem colocar suas cartas especiais na mesa e aquele que puder capturar todas as cartas e relacioná-las corretamente com o seu algoritmo, ganha a rodada e vencedor será aquele que tiver mais rodadas vencidas. $\mathrm{O}$ autor destaca a importância do aprendizado colaborativo durante o jogo, uma vez que os jogadores discutem as questões buscando as respostas de modo a continuar no jogo.

A principal diferença entre o jogo RPG4Sorting, proposto neste trabalho, e aqueles propostos por Boticki et al. (2012) e Battistella et al. (2012) é que o $R P G 4$ Sorting é um jogo não digital, com enfoque na colaboração em tempo real entre os jogadores. A ideia de desenvolver um jogo RPG de tabuleiro, como o RPG4Sorting, visa alcançar os benefícios do aprendizado colaborativo, assim como foi feito no trabalho de Hakulinen (2011). Uma diferença entre a proposta deste trabalho e de Hakulinen (2011) é que, segundo Bezakova et al. (2013), jogos de tabuleiro fornecem um contexto natural para a introdução de Estruturas de Dados e Algoritmos, assim como o seu layout e sua forma de jogar em turnos por exemplo, onde cada qual tem sua vez de jogar.

\section{RPG4Sorting}

Segundo Hitchens e Drachen (2009) as pessoas sabem quando estão jogando um RPG e sabem quando um jogo não é um RPG, porém ainda não há uma definição comumente aceita para essa categoria de jogo. A definição utilizada neste trabalho é que [Tarouco et al., 2004]:

“[...] um RPG é um jogo em que o usuário controla um personagem em um ambiente. Nesse ambiente, seu personagem encontra outros personagens e com eles interage. Dependendo

http://nihao.fer.hr/sortko/

3 http://www.inf.ufsc.br/ awangenh/sorting/HeapGame/ 
das ações e escolhas do usuário, os atributos dos personagens podem ir se alterando, construindo dinamicamente uma história."

Para existir um RPG são necessários quatro elementos: (i) um gamemaster (o mestre do jogo), (ii) um ou mais jogadores, (iii) a interação entre os jogadores; e (iv) o diegetic framework (as metas introduzidas pelo gamemaster) [Hitchens e Drachen, 2009].

\subsection{Apresentação do jogo}

O jogo RPG4Sorting se passa em um mundo onde cada jogador tem como objetivo treinar dragões, afim de que eles cresçam e tenham sua vida e experiência maior, a fim de garantir sua sobrevivência. Diferentemente dos RPGs tradicionais, os jogadores no mapa não são aliados entre si, mas sim adversários. O jogo necessita de, no mínimo, dois jogadores e, no máximo, quatro, que podem jogar simultaneamente. Além destes, há também um jogador extra, considerado o mestre do jogo (game master), cujo papel é coordenar, auxiliar e fiscalizar jogadas (diegetic framework); esse papel é indicado para o professor da disciplina, porém também pode ser ocupado por um monitor de disciplina ou por outro aluno que já possui um conhecimento mais sedimentado sobre o assunto.

Ao iniciar o jogo, o mestre distribui para cada jogador uma única carta que contém um filhote de dragão (Figura 1). Nesta carta, é possível observar o nome do dragão e seus respectivos pontos de vida (representado pelo coração) e de experiência (representado pela estrela). Todos os jogadores recebem dragões diferentes, entretanto, o número de vida e experiência é o mesmo para todos. O dragão evolui à medida que for acumulando experiência e para conquistar estes pontos o jogador deve enfrentar os desafios propostos no jogo.

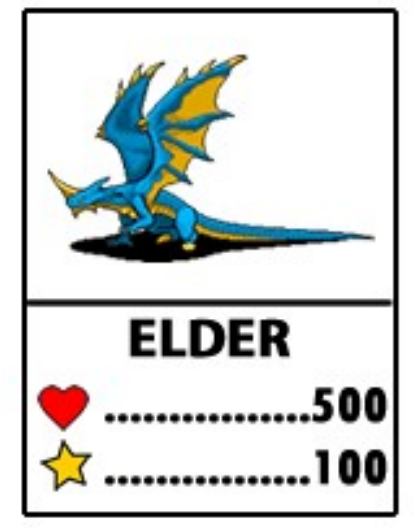

Figura 1. Exemplo de carta com um dragão, que cada jogador recebe no início do jogo.

Para iniciar o jogo, todos os jogadores devem lançar os dados e aquele que tirar o menor valor será o primeiro a jogar, o segundo menor valor será o próximo e assim sucessivamente. Em seguida, cada jogador irá escolher um personagem para se representar no tabuleiro; são quatro personagens distintos, cada qual representado por um caçador de dragões. Antes de iniciar o jogo, cada jogador deverá posicionar seu personagem nos números de 1 a 4 do tabuleiro (Figura 2), de acordo com a ordem determinada anteriormente. Ao lançar o dado, o jogador deverá andar na trilha do tabuleiro o número de quadros representados pela soma dos números retirados nos dois dados. 


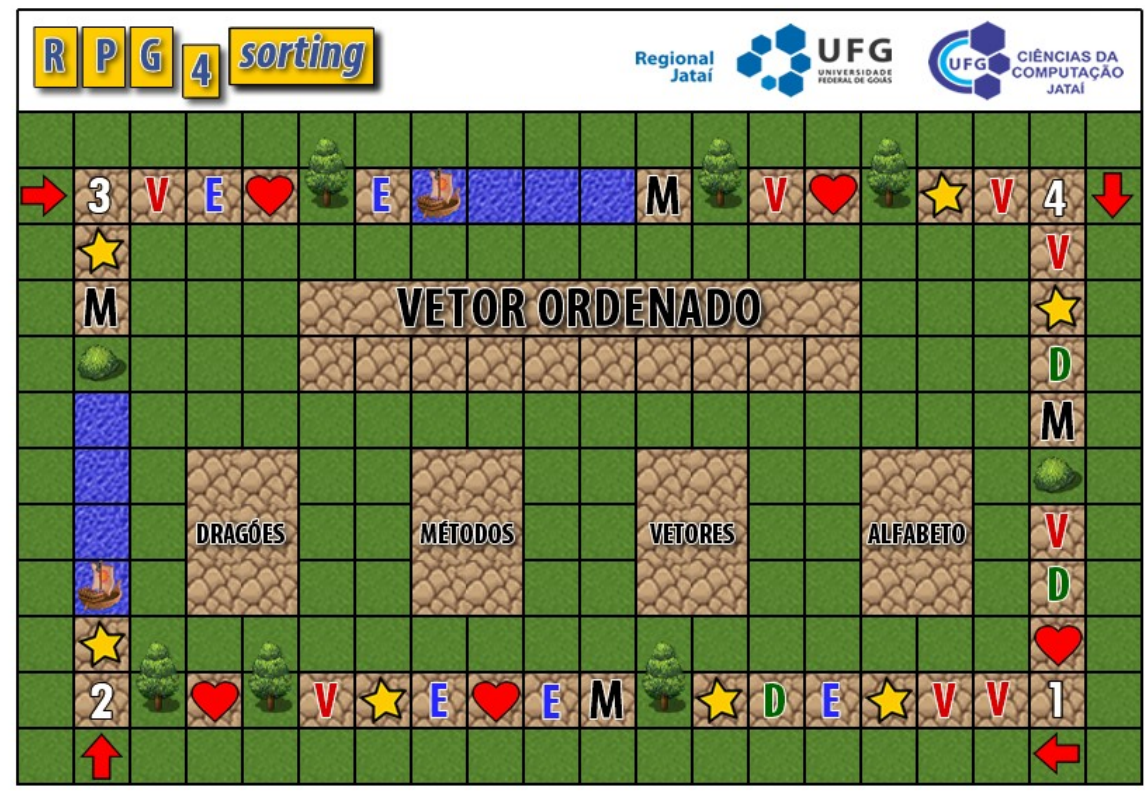

Figura 2. Tabuleiro do jogo.

Existem inúmeras situações com as quais o personagem pode se deparar ao longo do jogo. Se o jogador parar sobre uma casa do tabuleiro com a letra V (de "Vetor"), o mestre irá selecionar uma carta que terá o nome de um método de ordenação, que pode ser: Inserção (Insertion Sort), Bolha (Bubble Sort), Seleção (Selection Sort) ou Quick Sort. Após escolher o método, uma carta contendo um vetor a ser ordenado também será selecionada. Essas cartas estão no meio do tabuleiro viradas para baixo.

A Figura 3 apresenta um exemplo de uma "carta vetor". A partir deste momento, o jogador deve copiar o vetor contido na carta para o meio do tabuleiro, abaixo do título "Vetor Ordenado" (Figura 2).

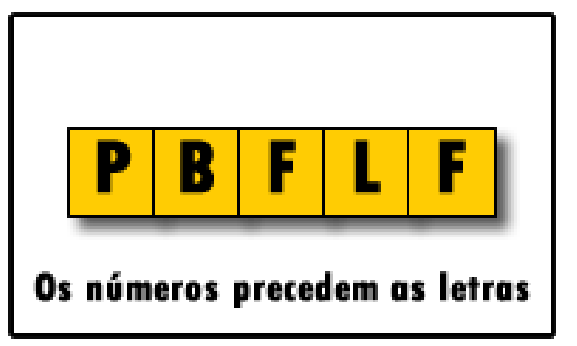

Figura 3. Uma das cartas contendo um vetor a ser ordenado.

O jogo inclui diversas cartas contendo letras do alfabeto e números de 0 a 9 . É por meio dessas cartas que o jogador irá copiar cada elemento contido na carta vetor para a área disponível no tabuleiro, na ordem em que eles aparecem na carta. Há também uma carta com o desenho de uma seta, cujo intuito é auxiliar o aluno para que este não se perca nas iterações do método de ordenação. A seta pode ser utilizada livremente, de acordo com a necessidade do aluno. Um exemplo de uso dessa seta é para lembrar qual é o próximo elemento a ser ordenado em uma iteração ou qual é o elemento pivô ${ }^{4}$ do vetor, por exemplo.

Uma vez copiado o vetor para o centro do tabuleiro, o aluno deverá ordená-lo, de acordo com o método selecionado, sob a fiscalização dos seus adversários e do mestre. A cada erro de aplicação do método apontado pelos outros jogadores ou pelo mestre, o aluno perde 5 unidades da vida do seu dragão. Ao finalizar a ordenação, o jogador recebe um adicional de 100 pontos na experiência do seu dragão. A Figura 4 apresenta

4 Pivô é um termo utilizado no método de ordenação QuickSort para descrever o elemento que será o ponto de partição do vetor a cada iteração do método. 
os três primeiros passos do processo de ordenação do vetor $[\mathrm{P}, \mathrm{B}, \mathrm{F}, \mathrm{L}, \mathrm{F}]$, utilizando o método de ordenação por bolha (BubbleSort).

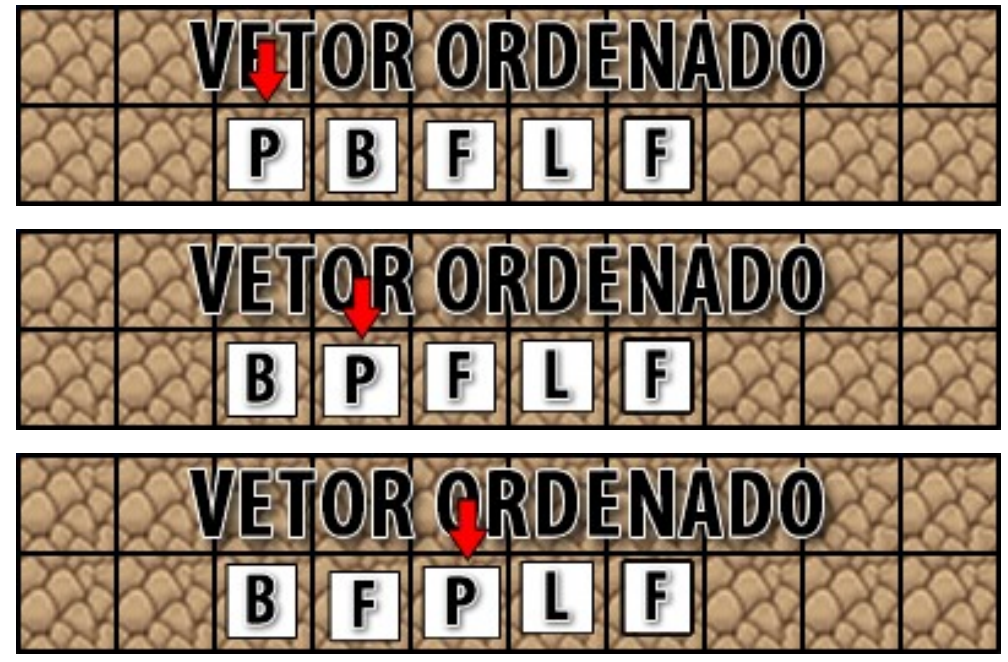

Figura 4. Três primeiros passos a serem realizados pelo aluno para ordenação de um vetor com o método de ordenação por bolha.

O jogador pode encontrar bônus espalhados no tabuleiro. Se ele parar sobre uma casa com o símbolo de uma estrela por exemplo (Figura 2), este receberá um adicional de 50 pontos de experiência. Ele pode parar também sobre uma casa com o símbolo de um coração, que provê um adicional de 50 pontos de vida. Há ainda o auxílio do mestre, representado pela casa com a letra "M", ou seja, se na próxima jogada o jogador for resolver um vetor, ele tem o direito de receber ajuda/dicas do mestre. Também existe a possibilidade de "fugir" da ordenação de um vetor; isso ocorre quando o jogador para sobre uma casa com o desenho de uma árvore ou arbusto, que faz a alusão de um jogador se escondendo atrás do arbusto ou no topo da árvore.

Uma casa com a letra " $D$ " significa que o jogador deverá ordenar um vetor sem qualquer erro de movimentação dos itens. Se ele obtiver sucesso, o mestre deverá entregar mais um dragão para o jogador; cada jogador poderá ganhar apenas um dragão extra. No caso da letra "E", o jogador terá o direito de escolher qual o método de ordenação ele deseja utilizar. Por fim, caso o jogador pare sobre uma das casas azuis (semelhante a um pequeno rio) ou sobre o barco, o jogador deverá resolver um vetor para pagar o dono do barco a fim de atravessá-lo, a cada erro o jogador perde 8 unidades de vida.

Outra possibilidade é a de dois jogadores se encontrarem em uma mesma casa. Neste caso, os dois deverão resolver o mesmo vetor, com métodos de ordenação diferentes, sorteados pelo mestre. Ambos vão receber as penalizações pelos erros na ordenação, entretanto somente aquele que acertar mais iterações receberá um adicional de 100 pontos de experiência; em caso de empate, os jogadores receberão 50 pontos de experiência cada um.

Se o jogador zerar os pontos de vida dos seus dragões ele deverá deixar o jogo, e o mesmo continuará até restar somente um jogador ou até que um dos jogadores acumule 1.500 pontos de experiência em um dos seus dragões primeiro; este será o vencedor. Um jogador também pode ser declarado vencedor se for o único jogador restante, ou seja, todos os outros jogadores já saíram do jogo.

\subsection{Elementos educacionais}

O jogo RPG4Sorting apresenta aspectos de imersão, interatividade, complexidade crescente e análise de atuação. Segundo Annetta (2010), tais elementos são necessários para que um jogo educacional alcance seus objetivos pedagógicos e corresponda às 
expectativas dos jogadores.

O conceito de estar imerso significa levar o jogador a ter uma identidade individual no jogo, ou seja, o fato de cada jogador possuir uma biografia que o induz a possuir um senso de presença no jogo. Nesse estado, ele se encontra envolvido no conteúdo do jogo e motivado a vencer os desafios [Annetta, 2010]. O fato de o RPG4Sorting trabalhar com a necessidade de acúmulo de pontos para vencer, contribui para que o jogador se encontre no processo de imersão, uma vez que ele deverá buscar cada vez mais, oportunidades de ganhar pontos, ou seja, ordenar os vetores com o mínimo de erros possíveis e aperfeiçoar suas habilidades frente aos outros jogadores.

A interatividade é o elemento que permite a interação com outros personagens em ambientes de múltiplos jogadores, por meio da comunicação e trabalho em equipe. Neste caso, o jogo proposto trabalha com a interatividade por meio da competição e também pelo trabalho em equipe, uma vez que o RPG4Sorting pode ser jogado por grupos de alunos. Por exemplo, dois grupos de três alunos que podem jogar como se fossem dois jogadores no mapa apenas, porém vão trabalhar juntos na ordenação dos vetores.

A complexidade crescente é definida pelos diferentes níveis de dificuldade presentes no jogo. Um bom jogo geralmente possui vários níveis de dificuldade que aumentam conforme o jogador vai desempenhando seu papel no jogo. É importante que o jogador sempre progrida e que ele seja recompensado por suas qualidades e decisões [Annetta, 2010]. No jogo RPG4Sorting, a complexidade pode ser observada nos diferentes métodos de ordenação, bem como no tamanho dos vetores propostos e nos desafios propostos (conseguir um novo dragão ou aumentar a experiência de um já existente, atravessar o rio, entre outros).

Por fim, a análise de atuação consiste no feedback e avaliações obtidos no contexto do jogo, por parte do aluno e do professor. A análise de atuação é uma ferramenta importante para o professor, pois permite que ele verifique as facilidades dos alunos e onde eles tiveram mais dificuldades para superar os desafios do jogo [Annetta, 2010]. A análise de atuação é fornecida pelo mestre do jogo, uma vez que é ele quem faz as anotações de pontos perdidos e bônus concedidos, além de ser uma de suas atribuições verificar erros e acertos, e fornecer ajuda de acordo com as regras do jogo.

\section{Avaliação}

\subsection{Planejamento da avaliação}

A avaliação do jogo RPG4Sorting foi conduzida de acordo com o modelo de avaliação de jogos educacionais proposto por Savi et al. (2010). Este modelo tem seu foco em jogos que possam ser utilizados como material educacional para apoiar o processo de ensino e aprendizagem de conteúdos curriculares. Uma das vantagens deste modelo é que sua aplicação não consome muito tempo, uma vez que, em geral, não há tempo hábil para longas sessões de avaliações nas disciplinas.

O modelo procura avaliar se um jogo: (i) consegue motivar os estudantes a utilizarem o recurso como material de aprendizagem; (ii) proporciona uma boa experiência nos usuários (e. g. se ele é divertido); e (iii) se gera uma percepção de utilidade educacional entre seus usuários (ou seja, se os alunos acham que estão aprendendo com o jogo).

Para avaliação destes três aspectos Savi et al. propõe um questionário para coleta de dados sobre os parâmetros que formam o modelo de avaliação. O questionário é composto de 43 itens, apresentados na forma de afirmações para os alunos indicarem o quanto concordam com elas de acordo com uma escala Likert de 7 pontos variando de 
"discordo fortemente" até "concordo fortemente". Por questão de limitação de espaço, as questões do questionário foram omitidas deste texto, apresentando apenas os resultados por categoria. Contudo, o questionário completo, com as questões, bem como os resultados para as mesmas podem ser obtidos por meio do link: goo.gl/Y5h9YE.

A avaliação foi conduzida com 3 grupos de 4 alunos em diferentes dias, houve a preocupação em buscar alunos participantes que já tivessem concluído as disciplinas de Estruturas de Dados I e II. A avaliação realizada com o primeiro grupo de alunos foi considerada como um piloto, a fim de identificar falhas na abordagem de avaliação, bem como no roteiro do jogo. Neste piloto foi observado que, antes de iniciar o jogo, seria necessário ministrar um pequeno treinamento sobre a forma de ordenar os vetores no tabuleiro, especificando cada método presente no jogo. As avaliações realizadas no piloto foram desconsideradas no resultado final. Além disso, os alunos que participaram do piloto não fizeram parte das avaliações novamente.

Durante a avaliação efetiva do RPG4Sorting, cada grupo jogou por cerca de 30 (trinta) minutos, e após este período, todos os jogadores responderam ao questionário elaborado segundo o modelo proposto por Savi et al. (2010). Exemplos de questões existentes neste questionário são: "Houve algo interessante no início do jogo que capturou minha atenção", "Me esforcei para ter bons resultados no jogo", "Há poucas coisas no jogo que me irritaram", cada qual relacionada, respectivamente, com os três atributos cuja avaliação visa coletar informações, a saber, Motivação, Experiência do Usuário e Conhecimento.

Foi observado no modelo proposto por Savi et al. (2010) que algumas das questões de avaliação propostas apresentavam afirmações positivas e algumas afirmações negativas. Para manter a homogeneidade dos dados coletados, foi feita uma conversão destas afirmações para afirmações positivas, por exemplo a afirmação "Algumas coisas do jogo me irritaram" foi convertida para, "Há poucas coisas no jogo que me irritaram". Tais afirmações podem ser avaliadas de forma negativa igualmente, porém mantendo o padrão de que os números maiores representam uma maior concordância com a afirmação, e os números menores representam menor concordância com a afirmação.

\subsection{Análise dos resultados}

A Tabela 1 apresenta os resultados da avaliação do RPG4Sorting. Cada atributo do jogo (motivação, experiência do usuário e utilidade educacional) foi apresentado com base em seus subatributos, com o intuito de facilitar a interpretação dos resultados. As últimas três colunas da Tabela 1 representam, respectivamente, a porcentagem média de alunos que escolheram alternativas positivas (opções 5 à 7 da escala Likert), neutra (opção 4 da escala Likert) ou negativas (opções 1 à 3 da escala Likert) para afirmações relacionadas a cada subatributo do modelo de avaliação de Savi et al. (2010). Devido a limitações de espaço, apenas alguns dos atributos são comentados no texto.

Os subatributos de "Motivação" são: Atenção, Relevância, Confiança e Satisfação. A avaliação mostrou que houve uma grande concordância por parte dos avaliadores quanto aos subatributos atenção ( $94 \%$ de avaliações positivas) e confiança $(90 \%$ de avaliações positivas). A atenção refere-se às respostas cognitivas dos alunos aos estímulos instrucionais. A confiança refere-se à criação de expectativas positivas nos estudantes, ao proporcionar-lhes experiências de sucesso decorrentes de suas próprias habilidades e esforço [Savi et al., 2010]. A avaliação mostrou também que o atributo satisfação ( $72 \%$ de avaliações positivas) não foi avaliado tão bem quanto os anteriores. Segundo Savi et al. (2010), os alunos precisam ter sentimentos positivos sobre a experiência de aprendizagem, e isso pode vir por meio de recompensas e reconhecimentos. As propostas para melhorar os resultados deste atributo são adicionar novos tipos de recompensas no jogo e a possibilidade de oferecer dicas e cartas de ajuda 
aos jogadores.

Tabela 1. Média de avaliações por atributos do questionário.

\begin{tabular}{|c|c|c|c|c|}
\hline \multirow{2}{*}{\multicolumn{2}{|c|}{ ATRIBUTOS }} & \multicolumn{3}{|c|}{ AVALIAÇÕES } \\
\hline & & Positivas (5 até 7 ) & Neutras (4 apenas) & Negativas (1 até 3 ) \\
\hline \multirow{4}{*}{ MOTIVAÇÃO } & Satisfação & $72 \%$ & \begin{tabular}{|l|}
$16 \%$ \\
\end{tabular} & $13 \%$ \\
\hline & Relevância & $85 \%$ & $8 \%$ & $8 \%$ \\
\hline & Confiança & $90 \%$ & $3 \%$ & $8 \%$ \\
\hline & Atenção & $94 \%$ & $6 \%$ & $0 \%$ \\
\hline \multicolumn{2}{|r|}{ MÉDIA } & $85 \%$ & $8 \%$ & $9 \%$ \\
\hline \multirow{5}{*}{$\begin{array}{l}\text { EXPERIÊNCIA } \\
\text { DO USUÁRIO }\end{array}$} & Divertimento & $75 \%$ & $13 \%$ & $13 \%$ \\
\hline & Desafio & $80 \%$ & $10 \%$ & $10 \%$ \\
\hline & Imersão & $85 \%$ & $8 \%$ & $6 \%$ \\
\hline & Habilidade/Competência & $88 \%$ & $6 \%$ & $6 \%$ \\
\hline & Interação Social & $96 \%$ & $4 \%$ & $0 \%$ \\
\hline \multicolumn{2}{|r|}{ MÉDIA } & $85 \%$ & $8 \%$ & $9 \%$ \\
\hline CONHECIMENTO & Conhecimento & $88 \%$ & $4 \%$ & $4 \%$ \\
\hline
\end{tabular}

Foi para o atributo "Experiência do Usuário" que ocorreu o caso de maior sucesso na avaliação, pois o subatributo interação social recebeu $96 \%$ de avaliações positivas. Segundo Savi et al. (2010), o envolvimento com outras pessoas é um elemento de diversão nos jogos, e está relacionado com o sentimento de compartilhar um ambiente com outras pessoas e de se ter um papel ativo nele. Durante a avaliação do RPG4Sorting, os alunos interagiram entre si, ora com brincadeiras sobre quem seria o vencedor, ora comentando sobre os erros e acertos durante o processo de ordenação.

Há outro caso que merece atenção, a saber, o do subatributo divertimento $(75 \%$ de avaliações positivas). Alguns alunos relataram que, com o tempo, o jogo ficaria um tanto monótono, pois alguém sempre ordenaria um vetor e os outros jogadores esperariam o aluno em questão finalizar a sua jogada. Há algumas propostas para melhorar este subatributo: (i) adicionar tempo máximo para a ordenação dos vetores por parte dos alunos; (ii) permitir que um aluno continue a ordenação, caso outro aluno desista da mesma; (iii) oferecer ao jogador a opção de "roubar" um método considerado mais fácil de outro jogador; entre outras. Em média, o jogo foi bem avaliado pelos usuários, pois todos os três atributos principais receberam acima de $80 \%$ de avaliações positivas. Contudo faz-se necessário replicar o experimento com outros grupos de avaliadores, a fim de que os resultados possam ser generalizados com maior segurança.

\section{Considerações Finais}

O jogo proposto neste trabalho, RPG4Sorting, visa oferecer uma abordagem diferente da utilização de recursos textuais, visuais e digitais como apoio ao ensino de métodos de ordenação. A proposta é que este possa ser utilizado fora da sala de aula, isto é, fora do horizonte que os alunos contemplam todos os dias, e tentar aproximá-los do conteúdo educacional através da competição, da oferta de recompensa, do desafio, dentre outros elementos existentes no jogo.

A avaliação realizada com o jogo mostrou que o mesmo possui aceitação por partes dos seus usuários, a respeito da capacidade que o jogo tem de relacionar socialmente os alunos. Notou-se também, por meio da avaliação realizada, que há a necessidade de ajustes no jogo para que este consiga em, uma próxima avaliação, atingir uma média maior nos itens divertimento e satisfação, uma vez que ambos são importantes para a reputação, bem como utilização do jogo para com os alunos.

Nos dias atuais, existe um grande número de métodos de ordenação, porém o jogo proposto neste trabalho complementa somente quatro deles. Assim, como proposta para trabalhos futuros, além das mudanças já comentadas na Seção 4 deste trabalho, 
pretende-se incorporar novos tipos de métodos de ordenação ao jogo; todavia é necessário observar o nível de dificuldade dos métodos a serem adicionados e se o tabuleiro do jogo oferece suporte para a forma que o vetor será ordenado, se será utilizando um vetor ou se o método é melhor visualizado em formato de árvore. E por fim há também a necessidade de replicar o experimento com grupos maiores de alunos e em outros contextos, uma vez que muitas das perguntas do questionário são influenciadas pelo tipo de jogador que é o usuário testador.

\section{Referências}

Annetta, L. A. (2010) “The "I's' Have It: A Framework for Serious Educational Game Design”, In: Review of General Psychology, vol. 14, no. 2, p. 105-112.

Baker, R. S., Boilen, M., Goodrich, M. T., Tamassia, R. and Stibel, B. A. (1999) "Testers and Visualizers for Teaching Data Structures", In: SIGCSE '99 The proceedings of the thirtieth SIGCSE technical symposium on Computer science education, p. 261-265.

Barbosa, W. A. and Parreira Júnior, P. A. (2013) "Um Mapeamento Sistemático sobre Ferramentas de Apoio ao Ensino de Algoritmo e Estruturas de Dados", In: SBIE 2013.

Battistella, P. E., Von Wangenheim, A. and Von Wangenheim, C. G. (2012) "SORTIA - Um Jogo para Ensino de Algoritmo de Ordenação: Estudo de caso na Disciplina de Estrutura de Dados", In: SBIE 2012.

Benitti, F. B. V. and Molléri, J. S. (2008) "Utilização de um RPG no Ensino de Gerenciamento e Processo de Desenvolvimento de Software”, In: Anais do XXVIII Congresso da SBC (WEI'2008).

Bezakova, I., Heliotis, J. E. and Strout, S. P. (2013) "Board game strategies in introductory computer science", In: SIGCSE '13 Proceeding of the 44th ACM technical symposium on Computer science education, p. 17-22.

Boticki, I., Barisic, A., Martin, S. and Drljevic, N. (2013) "Teaching and learning computer science sorting algorithms with mobile devices: A case study, vol. 21, p. E41-E50.

Colaso, V., Kamal, A., Saraiya, P., North, C., McCrickard, S. and Shaffer, C. A., (2002) "Learning and Retention in Data Structures: A Comparison of Visualization, Text, and Combined Methods", In: World Conference on Educational Multimedia/Hypermedia and Educational Telecommunications (ED-MEDIA 2002).

Gibson, D., Aldrich, C. and Prensky, M. (2006) "Games and Simulations in Online Learning: Research and Development Frameworks", IGI Global, $1^{\text {th }}$ edition.

Hakulinen, L. (2011) "Card Games for Teaching Data Structures and Algorithms". In: Koli Calling '11 Proceedings of the 11th Koli Calling International Conference on Computing Education Research, p. 120-121.

Hitchens, M., and Drachen, A. (2008) “The Many Faces of Role-Playing Games". In: International Journal of Role-Playing, p. 3-21.

Júnior, J. C. R. P., Rapkiewicz, C. E., Delgado, C. and Xexeo. J. A. M. (2005) "Ensino de Algoritmos e Programação: Uma Experiência no Nível Médio", In: XIII Workshop de Educação em Computação (WEI'2005).

Savi, R., Von Wangenheim, C. G., Ulbricht, V., and Vanzin, T. (2010) "Proposta de um Modelo de Avaliação de Jogos Educacionais". In: RENOTE - Revista Novas Tecnologias na Educação, vol. 8, no. 3.

Silva, I. K. O. and Morais II, M. J. O. (2011) "Desenvolvimento de Jogos Educacionais no Apoio do Processo de Ensino-Aprendizagem no Ensino Fundamental”. In: HOLOS, vol. 5, p. 153-164.

Tarouco, L. M. R., Roland, L. C., Fabre, M. J. M. and Konrath, M. L. P. (2004) “Jogos educacionais”. In: http://www.cinted.ufrgs.br/ciclo3/af/30-jogoseducacionais.pdf

Wiedenbeck, S., LaBelle, D. and Kain, V. N. R. (2014) "Factors Affecting Course Outcomes in Introductory Programming", In: 16 th Workshop of the Psychology of Programming Interest Group, p. 97-110. 